\title{
A INEXISTÊNCIA DE UM SISTEMA ELEITORAL MISTO E SUAS CONSEQÜÊNCLAS NA ADOÇÃO DO SISTEMA ALEMÃO NO BRASIL
}

\author{
Luís Virgílio Afonso da Silva \\ Aluno do Curso de Pós-Graduação da Faculdade de Direito da USP
}

\begin{abstract}
Resumo:
O sistema eleitoral alemão sempre despertou a simpatia dos insatisfeitos com o atual modelo representativo brasileiro. E, não-só no Brasil, esse sistema eleitoral tem sido considerado como o paradigma de uma terceira categoria de sistema eleitoral, a dos sistemas mistos, que reuniria elementos dos dois outros ramos dos sistemas eleitorais, o majoritário e o proporcional. Chega-se, neste artigo, à conclusão de que essa terceira categoria de sistemas eleitorais não existe e que o sistema alemão pertence à categoria dos sistemas proporcionais, o que faz com que sua adoção no Brasil seja menos dificultosa do que aparenta.
\end{abstract}

\begin{abstract}
:
The german electoral system has always arousen the interest of those insatisfied with the present brazilian representative model. What is more, not only in Brazil, this electoral system has been considered as a paradigm of a third category of electoral systems, i.e., the mixed systems, which would combine elements of the two others branches of electoral systems, the majority and proportional systems. On this article it is possible to reach the conclusion that the mentioned third category of electoral systems does not exist and that the german system is inserted in the proportional representation category, which would decrease the difficulty of his adoption in Brazil.
\end{abstract}

Unitermos: Sistemas eleitorais misto e alemão; majoritário e proporcional.

\footnotetext{
* Este artigo foi feito com base nos resultados da pesquisa sobre sistemas eleitorais, feita pelo autor, sob orientação da Professora Fernanda Dias Menezes de Almeida, com o auxilio de uma bolsa da FAPESP - Fundação de Amparo à Pesquisa do Estado de São Paulo, entre abril de 1994 e junho de 1995.
} 
Sumário:

1. Delimitação da discussão.

2. Sistema distrital misto: carência de significado.

3. Métodos de classificação dos sistemas eleitorais: fonte do problema da hibridez.

4. O princípio representativo do sistema eleitoral alemão: a proporcionalidade.

5. Conclusão: requisitos formais para a adoção do sistema proporcional personalizado no Brasil.

6. Bibliografia.

1. Delimitação da discussão.

Mais uma vez nos vemos diante de propostas de mudanças em nosso sistema de eleição para a Câmara dos Deputados e, novamente, as discussões giram em torno do chamado sistema eleitoral misto, ou seja, do sistema eleitoral adotado na Alemanha. Muito já se discutiu a respeito das características, vantagens e desvantagens desse sistema, e não se quer aqui fazer mais um arrolamento de argumentos contrários ou favoráveis à mudança, nem tomar uma posição quanto ao sistema desejável para o Brasil. A proposta aqui é outra, um pouco mais teórica do que os debates entusiastas que ora endeusam ora massacram o sistema germânico. $\mathrm{O}$ que se fará aqui será uma crítica à própria categoria sistema eleitoral misto e, também, a terminologias que considero ainda mais errôneas, como sistema distrital misto. Mas a predominância do aspecto teórico-terminológico não-significa, obviamente, ignorar os resultados práticos que, no caso em questão, são altamente relevantes.

2. Sistema distrital misto: carência de significado.

A crítica começa pelo termo sistema distrital, do qual deriva a expressão sistema distrital misto. Criação, ao que parece, da doutrina brasileira, a expressão sistema distrital é absolutamente carente de valor distintivo entre os sistemas eleitorais, pois se refere apenas ao local onde a eleição será realizada no distrito -, mas não por qual método - majoritário ou proporcional. São sistemas distritais, dessa forma, tanto o proporcional brasileiro, no qual os distritos equivalem aos Estados, quanto o majoritário inglês, com seus distritos uninominais. Aqui no 
Brasil, no entanto, sistema distrital ficou sendo sinônimo de sistema majoritário em distritos uninominais, o que é absolutamente errôneo. Parece que tal equívoco vem da contraposição feita entre distrito, que seria a delimitação territorial onde se realizam aquelas eleições em que o vencedor é somente o candidato mais votado, e circunscrição, que seria a delimitação onde são realizadas as eleições proporcionais, com vários eleitos no mesmo espaço físico. Não há, contudo, qualquer fundamento para essa contraposição, porquanto as palavras distrito e circunscrição, sem qualquer qualificação, significam tão-somente uma delimitação territorial, independente de eleição, de número de eleitos ou de candidatos por partido, sendo, portanto, sinônimas.

Esclarecida a questão referente ao termo sistema distrital, carente de significado como se pode ver, parece-me que nada precisa ser repetido aqui para se fazer uma crítica ao malchamado sistema distrital misto. Isto porque esta locução também emprega o equivocado termo sistema distrital, apenas acrescentando-lhe o qualificativo misto. Valem, portanto, também para essa expressão as críticas feitas no parágrafo anterior, ficando para mais adiante a discussão sobre o caráter misto do sistema.

É claro que não é a primeira vez que são feitas críticas à expressão sistema distrital misto e nem será a última. Tampouco é esse o objetivo deste artigo. Ventilei aqui essa questão apenas porque tal imprecisão terminológica sempre fez com que a expressão sistema eleitoral misto, sem o qualificativo distrital, parecesse a mais apropriada para denominar o sistema eleitoral utilizado para o parlamento alemão. Como o que parecia estar defeituoso era tão-somente o elemento distrital do termo, a expressão sistema eleitoral misto resolveria bem o problema e seria a mais apropriada para o caso.

Não é esta, contudo, a posição que aqui se vai adotar, porquanto entendo que o sistema em vigor na Alemanha e proposto para o Brasil não é um sistema misto, mas proporcional. Para explicar esta afirmação, é necessário que se faça uma breve análise das características distintivas entre sistema majoritário e sistema proporcional. 
3. Métodos de classificação dos sistemas eleitorais: fonte do problema da hibridez.

Adoto aqui a classificação dos sistemas eleitorais feita por Dieter Nohlen, com a separação entre regra de decisão e princípio representativo, os quais explico mais adiante.

É comum ouvirmos as seguintes definições sobre os tipos de sistemas eleitorais: (a) nos sistemas majoritários, ganha o candidato que obtiver a maioria, absoluta ou relativa, dos votos; (b) nos sistemas proporcionais, a divisão dos mandatos é feita de forma a distribuí-los conforme o peso de cada força política em disputa.

As duas definições estão corretas, mas não é difícil perceber que cada uma delas utiliza um critério diferente de conceituação. Assim, quando se diz que nos sistemas majoritários ganha o candidato que obtiver a maioria de votos, está se fazendo uma classificação com base no método de transformação de votos em mandatos (regra de decisão). Já quando se fala que nos sistemas proporcionais os mandatos são atribuídos conforme a força de cada partido, está se procedendo a uma classificação com base no resultado do sistema (princípio representativo). ${ }^{1}$

Chega-se, então, à conclusão de que há duas formas de se proceder a uma classificação dos sistemas eleitorais, uma baseada na regra de decisão e outra no princípio representativo.

Vejamos então qual é a regra de decisão utilizada por cada um dos dois tipos básicos de sistemas eleitorais, para depois analisarmos quais são seus respectivos princípios de representação.

A regra de decisão utilizada pelos sistemas eleitorais majoritários é aquela segundo a qual ganha o candidato que obtiver a maioria dos votos. Já para os sistemas proporcionais, a regra de decisão é aquela que diz que eleitos são os candidatos ou partidos que alcançarem um determinado número de votos $(n)$, o que significa que um partido consegue tantos mandatos quantas vezes seu número total de votos contiver $n$. Nota-se que, agora, a classificação baseou-se em apenas um critério, qual seja, o método de transformação dos votos em mandatos (regra de decisão).

1. Cf. Dieter Nohlen, Wahlrecht und Parteiensystem: über die politischen Auswirkungen von Wahlsystemen, pp. 97, 102, 106 e passim. 

na adoção do sistema alemão no Brasil

Em se tratando do princípio representativo, pode-se dizer que os sistemas majoritários pretendem constituir uma maioria partidária, ainda que essa maioria esteja baseada em uma minoria de eleitores, enquanto que os sistemas proporcionais pretendem refletir no Parlamento, em uma proporção mais ou menos exata, a força de cada partido que entra na disputa.

Feita essa prévia explicação, duas perguntas fundamentais se colocam: (1) qual é a relação entre esses dois diferentes modos de se classificar os sistemas eleitorais? (2) quando a Constituição de um país prevê um determinado sistema eleitoral para as eleições de seu poder legislativo, qual critério deve ser levado em consideração?

(1) Os dois critérios se relacionam, segundo Dieter Nohlen, como meio e fim, sendo que a regra de decisão é um meio para se chegar ao princípio representativo desejado. ${ }^{2}$ Normalmente, os dois critérios acabam coincidindo, o que significa que os modelos eleitorais que adotam a regra decisória majoritária se ajustam ao princípio majoritário, o mesmo valendo para os sistemas proporcionais. Mas nem sempre isso ocorre. ${ }^{3}$

(2) Essa não-necessária coincidência entre meio e fim faz com que surja a dúvida sobre qual deles deve prevalecer. Parece claro que a regra de decisão tem uma importância secundária na opção por um sistema eleitoral, pois se há uma previsão constitucional sobre um sistema eleitoral, significa que os constituintes fizeram a opção por um princípio representativo e não por um simples método que pode, em alguns casos, não se coadunar com o princípio desejado. Assim, parece questionável a posição de Canotilho quando afirma, ao tratar do sistema eleitoral português, que "o sistema [adotado] deve ser em si mesmo proporcional, não bastando ser um sistema que dê resultados proporcionais". ${ }^{4}$ Faz ele essa ressalva acrescentando que, mesmo a Constituição portuguesa prevendo a eleição de acordo com o princípio de representação proporcional (art. 116, 5), ficaria afastada a hipótese de adoção do chamado sistema misto alemão, "ainda que este sistema possa

2. Idem, p. 106.

3. É o caso do sistema proporcional aplicado em circunscrições de pequeno tamanho (menos de seis eleitos). Nesse caso, apesar de ser aplicada a regra de decisão proporcional, os resultados são majoritários, sendo eleitos somente os candidatos dos partidos mais fortes. Cf, nesse sentido, Dieter Nohlen, Wahlrecht und Parteiensystem, p. 107; Idem, Wahlsysteme der Welt, p. 173 e ss.; Rein Taagepera \& Matthew Soberg Shugart, Seats and Votes, p. 112 e ss..

4. J. J. Gomes Canotilho, Constituição da República Portuguesa anotada, p. 628. 
assegurar resultados impecavelmente proporcionais'. 5

Fica claro, após o que já foi dito, que não-obstante poder haver uma enorme variação, e mesmo mistura, nos critérios de transformação de votos em mandatos (regra de decisão), devido à livre possibilidade de combinação de métodos, de novas construções de sistemas aritméticos etc., no campo do princípio representativo há somente duas opções, a serem escolhidas de maneira exclusiva: ou se busca a formação de maiorias parlamentares (princípio majoritário) ou se objetiva um poder legislativo que reflita de maneira mais ou menos fiel as diversas correntes de pensamento existentes na sociedade (princípio proporcional).

Fica claro, também, que quando se quer determinar se um sistema eleitoral é proporcional ou majoritário é o princípio representativo que deve ser levado em conta, ficando a regra de decisão como um simples meio de atingí-lo (caráter meramente instrumental da regra de decisão). Isto porque, frise-se, quando há uma escolha constitucional ou legal por um determinado sistema, o que se quer é que o princípio representativo desse sistema seja atendido, independente da fórmula adotada, porquanto não faria sentido apegar-se a uma regra de decisão, de caráter meramente técnico, se o princípio não fosse respeitado.

É esse o motivo pelo qual não se pode falar em sistemas mistos, porque mesmo que haja concomitantemente elementos majoritários e proporcionais no método de transformação de votos em cadeiras, um sistema eleitoral só pode atender a um princípio representativo, seja majoritário (formação de maiorias) seja proporcional (distribuição conforme a força de cada partido), sendo logicamente impossivel misturar os dois princípios, já que seria teratológico pensar em formação de maiorias e ao mesmo tempo refletir todas as correntes de pensamento em uma determinada sociedade.

4. O princípio representativo do sistema eleitoral alemão: a proporcionalidade.

Com as considerações feitas acima, e a compreensão de que não é possível se falar em um sistema que seja misto do ponto de vista do princípio representativo, resta analisar qual a situação do sistema alemão dentro desse contexto.

5. Idem, ibidem. No caso português a discussão é meramente teórica, pois a própria Constituição prevê a adoção do sistema de Hondt. 

na adoção do sistema alemão no Brasil

A tentativa de unir elementos dos sistemas majoritários e proporcionais foi, na Alemanha do pós-guerra, uma das formas de se evitar os problemas gerados pelo sistema proporcional da República de Weimar, o qual, segundo alguns, foi uma das principais causas da instabilidade política no entreguerras naquele país. ${ }^{6} \mathrm{E}$ é também essa aparente combinação de sistemas que levou a doutrina à criação de uma nova categoria entre os sistemas eleitorais, a dos sistemas mistos.

O modelo germânico tem, sim, elementos majoritários e proporcionais, mas somente na construção de sua regra de decisão. E isso, como já foi dito, não pode ser considerado como uma característica de mistura. Além disso, o elemento majoritário tem um papel tão-pouco decisivo na caracterização do sistema que, mesmo restringindo a análise à regra de decisão, perceberíamos que o elemento que define o sistema é o proporcional. Para demonstrar essa afirmação, é necessária uma explicação acerca do funcionamento técnico do sistema alemão:

a. cada Estado federado é dividido em um número de distritos igual à metade das cadeiras a que tem direito no Parlamento;

b. cada partido apresenta dois tipos de candidaturas: um candidato para concorrer à eleição majoritária uninominal no interior de cada um dos vários distritos e uma lista de candidatos com ordem previamente definida pelo partido (lista bloqueada), igual para todos os distritos de um determinado Estado (lista estadual);

c. cada eleitor dispõe de dois votos, referentes às duas formas de candidaturas: no primeiro deles, vota no candidato do seu distrito e, no segundo, em uma das listas partidárias;

d. para a definição de quantos mandatos cada partido tem direito, são utilizados somente os segundos votos, ou seja, os votos dados para a lista partidária. Para tal distribuição, utiliza-se um método proporcional, que na Alemanha é o método Hare/Niemeyer. É necessário frisar, para que não haja compreensões errôneas, que essa distribuição não se refere somente à metade das cadeiras a preencher, como muito se ouve dizer, mas ao total delas. Assim, se um Estado tem direito a trinta deputados no Parlamento, estas trinta vagas são distribuídas segundo o método proporcional;

e. a parte majoritária só é considerada quando do preenchimento das

6. Cf., nesse sentido: Emil Hübner, Wahlsysteme, p. 21 e 116; Peter Pulzer, "Germany", p. 84. 
vagas já distribuídas pelo método proporcional. Assim, após a definição do quociente partidário, isto é, do número de mandatos a que cada partido tem direito, o preenchimento das vagas é feito da seguinte forma: são considerados eleitos todos os candidatos que tenham vencido as eleições internas de cada distrito mais os $n$ primeiros nomes da lista partidária estadual, sendo $n$ o número necessário para se completar o quociente partidário.

Explicado o funcionamento do sistema, fica claro que a inserção da parte majoritária não-altera a forma como é feita a distribuição das cadeiras, ou seja, de acordo com a fórmula proporcional.

Concluindo este tópico, pode-se afirmar: se todos os mandatos são distribuídos de forma a que cada partido tenha um número de mandatos proporcional à sua força, isso significa que o sistema eleitoral alemão é um sistema que atende ao princípio representativo proporcional e que, por conseguinte, se insere na categoria dos sistemas proporcionais. ${ }^{7}$

Parece, então, ser importante que se adote outra expressão para se denominar o sistema eleitoral alemão, sendo a mais indicada para isso exatamente aquela utilizada onde o sistema foi criado, expressão que por si só já aponta para a inclusão do sistema entre os proporcionais. Afastando o equivocado termo sistema misto, passaríamos a utilizar a expressão sistema proporcional personalizado (personalisiertes Verhältniswahlsystem).

5. Conclusão: requisitos formais para a adoção do sistema proporcional personalizado no Brasil.

A Constituição brasileira, como grande parte das constituições ocidentais, não entra em detalhes quando trata do sistema de eleição para a Câmara dos Deputados. Prevê ela somente que deva ser atendido o princípio representativo proporcional, não havendo menção à regra de decisão a ser adotada, o que fica para a legislação ordinária. Diz o art. 45 da Constituição de 1988: "A Câmara dos Deputados compõe-se de representantes do povo, eleitos, pelo sistema proporcional, em cada Estado, em cada Território e no Distrito Federal".

7. Cf., com posições semelhantes, Dieter Nohlen, Wahlrecht und Parteiensystem, pp. 192 e 211; Kurt Sontheimer, Grundzüge des politischen Systems der Bundesrepublik Deutschland, p. 209; Klaus Von Beyme, Das politische System der Bundesrepublik Deutschland nach der Vereinigung, pp. $82 \mathrm{e}$ 83. 
Sempre que se cogitou da adoção do sistema proporcional personalizado, principalmente na malfadada revisão constitucional, a única solução que parecia cabível seria a votação de uma emenda constitucional, pelo fato do sistema alemão ser considerado um sistema misto, incompatível com a exigência constitucional de um sistema proporcional. Não me parece, contudo, ser necessária a adoção de tal procedimento. Para explicar, coloco agora três conclusões aqui tiradas, para após extrair uma consequiência que demonstrará a inexigibilidade de emenda constitucional para a adoção do sistema eleitoral alemão no Brasil.

(1) quando uma Constituição prevê a adoção de um determinado sistema eleitoral, sem entrar em detalhes de seu funcionamento técnico, ela faz referência a um princípio representativo e não a uma regra de decisão;

(2) a única exigência da Constituição brasileira a respeito do sistema de eleição para a Câmara dos Deputados é que o sistema seja proporcional;

(3) o sistema alemão é um sistema eleitoral proporcional, pois se coaduna com o princípio representativo proporcional (distribuição de mandatos proporcionalmente à força de cada partido).

Conclusão: o sistema eleitoral alemão se ajusta completamente aos preceitos estabelecidos pelo art. 45 da Constituição, não havendo, por isso, a necessidade de uma emenda constitucional para sua adoção no Brasil, bastando, para tanto, que se alterem as disposições da legislação ordinária sobre o tema. ${ }^{8}$

São Paulo, maio de 1996.

\section{Bibliografia.}

BEYME, Klaus von. Das politische System der Bundesrepublik Deutschland nach der Vereinigung. 6. Aufl., München, Piper, 1991.

CANotuho, José Joaquim Gomes \& MoreIRA, Vital. Constituição da República Portuguesa anotada. $3^{\mathrm{a}}$ ed., Coimbra, Coimbra Editora, 1993.

HÜBNER, Emil. Wahlsysteme und ihre möglichen Wirkungen unter spezieller Berücksichtigung der Bundesrepublik Deutschland. 6. Aufl., München, Bayerische Landeszentrale für Politische Bildungsarbeit, 1984.

NoHLEN, Dieter. Wahlrecht und Parteiensystem: über die politischen Auswirkungen von Wahlsystemen. Oplade, Leske, 1990.

Wahlsysteme der Welt: Daten und Analysen Ein Handbuch. 
München, Piper, 1978.

PUlzer, Peter, "Germany" in Bogdanor, Vernon \& BUTLer, David. Democracy and Elections: electoral systems and their political consequences. Cambridge, Cambridge University Press, 1983.

SONTHEIMER, Kurt. Grundzüge des Politischen Systems der Bundesrepublik Deutschland. 13. Aufl., München, Piper, 1989.

TAAGEPERA, Rein \& SHUGART, Matthew Soberg, Seats and Votes: the effects and determinants of electoral systems. New Haven, Yale University Press, 1989. 